\title{
Insight into the global phosphorus cycle from apatite in ash from the 2018 Kilauea eruptions
}

\author{
P.L. KING ${ }^{1 *}$, E.M. OBORSKI ${ }^{1}$ AND D.E. DAMBY ${ }^{2}$
}

${ }^{1}$ The Australian National University, Research School of Earth Sciences, Canberra ACT 2601 Australia.

${ }^{2}$ U.S. Geological Survey, Volcano Science Center, Moffett

Field, Mountain View CA 94043 USA.

(*correspondence: penny.king@anu.edu.au)

Volcanic ash eruptions are recognised as an important source of phosporus $(\mathrm{P})$ for the global $\mathrm{P}$ cycle, delivering $\mathrm{P}$ to soils and the ocean. At volcanoes, $\mathrm{P}$ is hosted in primary phases such as melt-precipitated apatite, glass and rarely other phases (e.g., sanidine with $5 \mathrm{wt} \% \mathrm{P}$ at Tolbachik volcano [1]). Data for $\mathrm{P}$ in volcanic gases is scarce and suggests concentrations on the order of $\sim 0.1-10$ 's ppm [2-3]. However, some condensates record higher P contents, as do some ash samples that include fragments formed by gas-solid (high $\mathrm{T}$ contact metamorphic) reactions in the conduit [4]. Interestingly, at atmospheric pressures and high temperatures $\mathrm{P}$ is readily released from $\mathrm{P}_{2} \mathrm{O}_{5}$ [i.e. it is 'volatile'; 5], but $\mathrm{P}$ is reasonably soluble in basaltic melts [6]. Here, we consider the role of P-bearing volcanic gas in condensation and gas/fluid-solid reactions.

We observed apatite crystals attached to sulfate-silica rinds and decorating the interior walls of glass vesicles in ash from the 2018 Kilauea eruptions. These crystals appear to have formed after the primary phases as a result of gas-rich fluid reactions with solid surfaces (rinds or glass). We propose that surface $\mathrm{Ca}$ has reacted with $\mathrm{P}$ in the gas phase to form these crystals. To test this hypothesis we modelled the formation of apatite using a Gibbs Free Energy minimization approach from a starting composition that included relevant gas and solid phases. The modelling shows apatite is effectively produced from reactions between P-bearing gases and solids. These results indicate that sequestration of $P$ in condensates or products of gas-solid reactions needs to be included in assessing the global $\mathrm{P}$ cycle and primary magmatic fluids may have more $\mathrm{P}$ than volcanic gases.

References: [1] Shchipalkina et al. 2019 Phys Chem Minerals 47, 1. [2] Zelenski et al. 2014 J Volc Geotherm Res 285, 136-149 [3] Zelenski et al. 2013 Chem Geol 357, 95116 [4] Obenholzner et al. 2003 in Volcanic Degassing, Oppenheimer et al. (ed) Geol Soc Lon Sp Pub 213, 123-148. [5] Muan \& Osborn, 1965. Phase Equilibria Among Oxides in Steelmaking. Addison-Wesley. [6] Toplis et al. 1994 Geochim Cosmochim Acta 58, 797-810. 